\title{
Screening for diabetic retinopathy
}

\section{Combined modalities seem to provide the best option}

Diabetic retinopathy is an important cause of blindness, ${ }^{1}$ and the British Diabetic Association has recently begun a nationwide campaign to increase awareness of the problem. Much blindness due to diabetes is preventable: if sight threatening retinopathy is detected in time then laser treatment can greatly reduce the progression to blindness. ${ }^{2}$ To detect those patients who require treatment the traditional recommendation is that every one to two years all diabetic patients should be screened either by ophthalmoscopy through pharmacologically dilated pupils or by retinal photography. ${ }^{3}$

But concern is increasing that this advice is insufficient and the Department of Health and Social Security in the late 1980 s mounted the largest British study of the subject, which recruited 3318 patients to evaluate possible screening modalities. ${ }^{4}$ This study showed that ophthalmoscopy through dilated pupils (whether by general practitioners, optometrists, or hospital physicians) and retinal photography through undilated pupils both missed between one third and two thirds of cases of sight threatening diabetic retinopathy. The study concluded, "in a setting close to routine screening, the sensitivities of all screening methods are poor ...., the routine use of any of these single screening methods will fail to detect a large proportion of cases of sight threatening diabetic retinopathy." ${ }^{4}$

Similar results have been found in other studies. ${ }^{5}$ These studies, and a study showing that ophthalmologists and diabetologists may miss appreciable amounts of sight threatening diabetic retinopathy if allowed only dilated ophthalmoscopy in routine screening, ${ }^{6}$ suggest that ophthalmoscopy is unreliable as a means of screening, no matter who does it.

The Department of Health's study that suggested that $45^{\circ}$ field retinal photography was as unreliable as ophthalmoscopy for screening for retinopathy used retinal photography through undilated pupils. ${ }^{4}$ This was because the $45^{\circ}$ field cameras were being marketed at the time as "non-mydriatic." Diabetic patients tend to have abnormally small pupils as a manifestation of autonomic neuropathy, ${ }^{78}$ and small pupils lead to poor quality photographs. As the complications of diabetes tend to cluster in the same patients, ${ }^{9}$ the patients with autonomic neuropathy and abnormally small pupils are more likely to be the ones who have diabetic retinopathy.

Studies of "non-mydriatic" retinal photography have shown that when it is used in diabetic patients poor quality photographs occur in about a quarter..$^{1011}$ Studies using the same cameras through pharmacologically dilated pupils have shown that the photographic quality is greatly improved. ${ }^{11} 12$ Had retinal photography through pharmacologically dilated pupils been included in the Department of Health's study much less sight threatening diabetic retinopathy might have been missed. Nevertheless, the possibility of sight threatening diabetic retinopathy beyond the field of the standard $45^{\circ}$ photograph exists. ${ }^{13}$

Another large study of 2159 patients showed that both ophthalmoscopy and retinal photography miss considerable amounts of sight threatening diabetic retinopathy detected by the other technique. ${ }^{14} \mathrm{~A}$ report has recently been published of combined ophthalmoscopy and retinal photography, both through dilated pupils, performed by a trained technician. ${ }^{15}$ Though this study lacked full assessment by an ophthalmologist of all 1050 diabetic patients, close agreement existed between the assessment of the technician and the ophthalmologist's assessment based on the photograph; the technique seemed to have high specificity: among 45 patients suspected of having sight threatening diabetic eye disease on the basis of screening, only one referral was thought inappropriate.

Combined dilated retinal photography and ophthalmoscopy have also been adopted in west Birmingham, where the screening is done by specialist optometrists highly experienced in diabetic retinopathy. The optometrist can call on a diabetologist to discuss cases of doubt while the patient is still present with eyes dilated. An audit of this system presented recently to the British Diabetic Association suggested that the combined modalities in this setting have abolished the problem of appreciable amounts of sight threatening diabetic retinopathy being missed by ophthalmoscopy alone and have also generated a sensitive system for detecting diabetic retinopathy in general. ${ }^{16}$ Other centres are adopting dual screening systems and are finding them similarly successful. ${ }^{17}$

Those who plan screening programmes for diabetic retinopathy should be aware that either ophthalmoscopy through dilated pupils alone or retinal photography through undilated pupils will miss between one third and two thirds of cases of sight threatening diabetic retinopathy, even if performed by an experienced ophthalmoscopist. They should also bear in mind a patient who claimed that she had gone blind because her retinopathy had not been adequately detected or treated and who recently settled her case out of court, receiving $£ 225000$ from her health authority. ${ }^{18}$

The cost of litigation may dwarf into insignificance the cost of providing screening programmes combining the mutual 
benefits of ophthalmoscopy and retinal photography through dilated pupils with screening being administered by experienced personnel. BOB RYDER

Diabetic Unit,

City Hospital,

Birmingham B18 7QH

\footnotetext{
1 Department of Health and Social Security. Causes of blindness and partial sight among adults in

England in 1976/77 and 1980/81. London: HMSO, 1988.
2 Kohner EM. Diabetic retinopathy. BM7 1993;307:1195-9.

3 Retinopathy Working Party. A protocol for screening for diabetic retinopathy in Europe. Diabetic Med 1991;8:263-7.

4 Buxton MJ, Sculpher MJ, Ferguson BA, Humphreys JE, Altman JFB, Spiegelhalter DJ, et al. Screening for treatable diabetic retinopathy: a comparison of different methods. Diabetic Med $1991 ; 8: 371-7$.

5 Finlay R, Griffiths J, Jackson G, Law D. Can general practitioners screen their own patients for diabetic retinopathy? Health Trends 1991;23:104-5.

6 Foulds WS, MacCuish AC, Barrie T, Green F, Scobie IN, Ghafour IM, et al. Diabetic retinopathy in the west of Scotland: its detection and prevalence, and the cost-effectiveness of a proposed screening programme. Health Bull 1983;41:318-26.

7 Smith SE, Smith SA, Brown PM, Fox C, Sonksen PH. Papillary signs in diabetic autonomic neuropathy, $B M F$ 1978;ii:924-7.
}

8 Smith SA, Smith SE. Reduced pupillary light reflexes in diabetic autonomic neuropathy Diabetologia 1983;24:330-2.

9 Krolewski AS, Barzilay J, Warram JH, Martin BC, Pfeifer M, Rand LI. Risk of early-onset proliferative retinopathy in IDDM is closely related to cardiovascular autonomic neuropathy. Diabetes 1992;41:430-7.

10 Ryder REJ, Vora JP, Atica JA, Owens DR, Hayes TM, Young S. A possible new method to improve detection of diabetic retinopathy: Polaroid non-mydriatic retinal photography. $B M F$ 1985;291:1256-7.

11 Jones D, Dolben J, Owens DR, Vors JP, Young S, Creagh FM. Non-mydriatic Polaroid photography in screening for diabetic retinopathy: evaluation in clinical setting. BMF 1988;296:1029-30.

12 Ryder REJ, Griffiths H, Moriarty KT, Kennedy RL, Blumsohn A, Hardisty CA. Superimposing retinal photography with a $4 \mathrm{~mm}$ pupil camera on existing retinopathy screening services in the diabetic clinic. Practical Diabetes 1991;8:151-3.

13 Barrie R, MacCuish AC. Assessment of non-mydriatic fundus photography in detection of diabetic retinopathy. $B M Y$ 1986;293:1304-5.

14 Taylor R, Lovelock L, Tunbridge WMG, Alberti KGMM, Brackenridge RG, Stephenson P, et al. Comparison of non-mydriatic retinal photography with funduscopy in 2159 patients: mobile retinal camera study. $B M \mathcal{F}$ 1990;301:1243-7.

15 Jacob J, Stead J, Sykes J, Taylor D, Tooke JE. A report on the use of technician ophthalmoscopy, combined with the use of the Canon non-mydriatic camera in screening for diabetic retinopathy in the community. Diabetic Med 1995;12:419-25.

16 Ryder REJ, Close CF, Gray MD, Souten H, Gibson JM, Taylor KG. Fail-safe diabetic retinopathy detection and categorisation by experienced ophthalmic opticians combining dilated retinal photography with ophthalmoscopy. Diabetic Med 1994;11(suppl 2):S44.

17 Smith SA, Shilling JS, Hull DA, Lowy C, Sonksen PH. Two year audit of primary care eye screening service in diabetes. Diabetic Med 1994;11(suppl 1): S23.

18 Brahams D. Medicine and the law: eye monitoring in diabetes. Lancet 1992;339:863-4.

\title{
The boundary between health care and social care
}

\author{
A positive but insufficient step
}

The Department of Health's recent guidance NHS Responsibilities for Meeting Continuing Health Care Needs ${ }^{1}$ merits a cautious welcome. It follows a much criticised draft, ${ }^{2}$ which originated in the health service commissioner's upholding of a complaint that Leeds Healthcare had failed to provide long term NHS care for a brain damaged patient. ${ }^{3}$ Even so, it does not resolve all the uncertainties about responsibilities at the boundary between health and social care. Still less does it acknowledge the silent, if not surreptitious, shift in the balance between state and individual responsibilities for funding long term care that has taken place over the past 15 years. The profound implications of that shift for the expectations and finances of the current generation of elderly people and their families justify a long overdue public review of the current arrangements and their consequences. ${ }^{4}$

On the more positive side, however, the final guidance can be seen as more substantial, comprehensive, and prescriptive than its draft precursor. In a climate of increasing concern about pressure on resources in the acute sector and emergency medical admissions ${ }^{5}$ its overt commitment to continuing care as an "integral part of the NHS" is a welcome and important statement of intent. Especially important is the requirement that district health authorities and fundholders should invest in continuing health care when they are "failing currently to arrange and fund a full range of services." The Department of Health clearly intends NHS responsibilities for continuing care to be fulfilled rather than evaded.

Although falling short of providing national minimum standards, the detailed guidance sets out nine issues that local purchasing policies and criteria for eligibility should cover. The inclusion of rehabilitation and recovery, palliative health care, and respite health care and specialist transport merits particular welcome as clarification of the NHS's responsibilities and extension of the draft guidance.

Although much in the guidance is commendable, much is also deserving of caution. In the striking absence of references to funding, reinvestment in continuing care will imply disinvestment from other areas. The NHS Executive will monitor planned and achieved levels of spending and activity annually, but how it will ensure the commissioning of a full and adequate range of local services is not clear. Hopefully, innovative purchasers will develop new policies and models of continuing care, breaking the long established mould of hospitals and nursing homes. Where such energy and vision are lacking, however, the lack of more specific guidance may result in a return solely to block contracts for long term beds, whether in the NHS or in the independent sector.

Criteria for eligibility will be set locally, resulting inevitably in local variations for people with identical or similar needs, although patients or their carers will have the right to seek review of decisions regarding eligibility before discharge from hospital. Ambiguities and local inconsistencies in criteria for eligibility take on a unique significance at the boundary of health and social care, since care commissioned by the NHS is received free at the point of delivery but that commissioned by local authorities may be subject to charges and means tests of savings and capital, including people's homes. These local criteria will distinguish between patients deemed eligible for care funded by the NHS as inpatients in hospitals or nursing homes (category E) and those identified as requiring "access to specialist or intensive medical and nursing support" while in nursing or residential home care funded by local authorities (category G). The consequences of these crucial but difficult distinctions will be twofold, affecting, firstly, the distribution of costs for residential and nursing home care between the NHS and local authorities and, secondly, the financial costs of continuing care borne directly by individuals and their families.

These locally defined distinctions and boundaries involve three, rather than two, categories: medical, nursing, and social care. ${ }^{6}$ Very difficult decisions will be required in respect of both medical and nursing care. For example, what will distinguish between "the need for frequent, not easily predictable interventions" requiring the regular (weekly or less) supervision of a consultant, specialist nurse, or other NHS member of the multidisciplinary team (category E) and the need for "regular access" including "occasional continuing specialist advice or treatment" from medical, nursing, or other community health services (category G)? In addition, the difficult distinction needs to be made between some aspects of domiciliary nursing care and 